\title{
MULTICULTURAL COMPONENT IN THE SYSTEM OF PROFESSIONAL TRAINING OF TOURISM AND HOSPITALITY MANAGERS IN CANADIAN UNIVERSITIES: EXPERIENCE FOR UKRAINE
}

\author{
Nataliia Zhorniak (Corresponding author), \\ Mariana Havran, Olena Barabash, Hanna Shayner, Oksana Bilyk
}

\author{
Lviv Polytechnic National University, Lviv, Ukraine \\ natalia.ye.zhorniak@lpnu.ua
}

\begin{abstract}
The article deals with tourism and hospitality managers' professional training in Canada. The authors analyse the scientific and pedagogical literature which highlights different aspects of the problem of multicultural component in the system of professional training of tourism and hospitality managers. The research methodology comprises theoretical and applied methods (bibliographical method, analysis and systematisation, content analysis, statistical analysis, synthesis and comparative analysis, mathematical method). The development of tourism and hospitality managers' professional training is outlined and the emergence of the need for its multicultural component formation is specified. The analysis of tourism occupational standards made it possible to distinguish the knowledge, skills and professional values of tourism and hospitality managers. The formation of the multicultural component, the content, objectives, and priorities of multicultural training are based on three main principles of multicultural education: accessibility, equal opportunities, diversity. The article describes the theoretical and applied elements of multicultural component formation as well as basic forms of organisation: the development of special courses, including additional content elements in curricula and academic programmes, the use of innovative forms and methods of training. The proposals for possible ways to adapt Canadian tourism and hospitality managers' professional training experience in Ukraine are developed.
\end{abstract}

Keywords: multicultural component; multicultural component formation; professional training of tourism and hospitality managers; university; Canada.

\section{Introduction}

Nowadays the growing expansion of tourism is a global tendency caused by the intensification of the range of cultural and spiritual needs, globalisation and advancement of the economic system, political, cultural and communication binds, as well as the development of communication means. Obviously, mass travelling of people into other cultural environment accelerates the process of both economic and cultural cooperation and increases the intensity of intercultural communication.

Social and economic changes taking place around the world have caused profound structural changes in tourism and hospitality industry. Consequently in many developing countries, including Ukraine, a whole complex of challenges arises, resulting from drawbacks in organisation, planning and governance of tourism and hospitality industry, its spontaneous development, the growth of luxury and international tourism and simultaneous reduction of mass, social, and national tourism, inadequate training of personnel and lack of scientific forecasting of sustainable tourism and hospitality industry development. These challenges reflect the growing needs of the population in tourism services on the one hand and insufficient level of satisfying them with the existing means of tourism and hospitality industry on the other. They are caused by changes in the competitive situation and the lack of competence of personnel in different spheres of tourism and hospitality activity. The managerial, economic, ecological and legal competencies require the improvement of professional tourism and hospitality managers' training.

Significant role in the development of the model of professional activities in tourism and hospitality industry is played by scientific researches. According to the international sociological research "Tourism Industry Association of Canada and Vise Canada" (2012), there were more than 603,000 jobs in more than 157,000 occupations in Canadian tourism industry in 2012, and the flow of foreign tourists has increased by $4.2 \%$ providing $17 \%$ income from export services. This country has profound experience in introducing multicultural component into tourism professional training. Particular attention is paid to the education of the indigenous population and this has a positive impact on the development of remote areas. Considering these facts, we chose Canada and its experience in professional tourism and hospitality managers' training (THM training) as a research object. Furthermore, multiculturalism as a component of professional THM training system is of our special research interest.

The academic training process of internationally recognised and highly qualified specialists requires the improvement of academic programmes reflecting the needs for multicultural environment and dialogue of cultures and business. In view of the important role and value of multiculturalism, its role and value in the system of professional THM training needs to be adequately studied. 
The problems of professional education, its content and nature were studied by Mukan, Kravets, and Khamulyak (2016). The fundamentals of tourism and hospitality management, as well as tourism and hospitality managers' professional training were researched by Orton (2001), Zagonari (2009). Theoretical and methodological principles of multicultural education were analysed in the scientific works of Banks (2010), Hossain and Aydin (2011), etc. Theoretical and methodological aspects of multiculturalism in tourism and hospitality sphere were highlighted in the studies of Manoharan, Singal (2017), Grobelna (2015). Tourism was defined as a means of cultural interaction in works of Raymond and Hall (2008), MacLaurin (2008), Percival, Cozzarin, and Formaneck (2013) studied specific features of professional THM training in Canada.

The importance of substantiation of theoretical and methodological background of multiculturalism in the system of professional THM training in higher education institutions of Ukraine and the lack of thorough research in this sphere determined the choice of our research theme.

The analysis presented in this article is drawn from a broader qualitative study examining the specific features of professional THM training in Canada. The aim of this paper is to present the results of the study of specific features of multicultural training as a component of professional THM training system in Canada.

According to the aim of our research, we used theoretical and applied research methods: the bibliographical method, analysis, and systematisation - for studying and forming the research database; content analysis, statistical analysis, synthesis and comparative analysis - to research the academic documentation of Canadian universities (programmes, curricula, handbooks, etc.); applied mathematical methods (registration, ranking, samples) - to obtain accurate statistical data about the academic process.

\section{Theoretical and methodological fundamentals of multicultural component in HTM training}

Multicultural study is a trend that has outstanding possibilities to help people in the fight against racial, social, gender and age inequality and enables them to become active members of a democratic society (Hossain, Aydin, 2011).

Philosophic and methodological fundamentals of multicultural education are grounded on critical pedagogy, the theory of global interdependence (Bethal, 1983; McLuhan, 1989), race identity theory (Cross, 1991; Helms, 1990), intergroup contact theory (Allport, 1963), etc.

In terms of tourism professional training, we can look upon globalisation as a multicultural issue. To avoid the intercultural misunderstanding it is necessary to consider diversity as a skill. The development of this skill raises awareness of one's own cultural values and biases, and helps to learn to value other people's worldviews (Bethal, 1983).

Research into the theory of racial identity has a long history. Cross (1991) and Helms (1990) contributed to the development of multiculturalism. They believe that social influences which hinder the development of human identity can cause problems for an individual and consequently the society as a whole.

Allport (1963) identifies intergroup contact theory, claiming that the bias of the majority towards the minority can be reduced by achieving equal status in the common interest, particularly when an educational institution supports this process. Under the term "support" of the educational institution, we mean legislation, customs or local community attitudes. Such support can complement the idea of the presence of common interests and sensible and peaceful human interaction among all community members.

In our research, we define tourism as business, leisure, communication, education, profession and even lifestyle. Since the beginning of the 21 st century, there has been a significant trend in cultivating tourism industry as increasingly attractive sector, which meets the spiritual needs of an individual. Thus, the concepts of culture and tourism are tightly interrelated. A modern tourist is becoming more and more demanding, better informed, which in turn makes the tourism industry consider the importance of the cultural component of tourism.

We define the essence of multicultural training as identifying differences and taking them into consideration in the academic learning process. Such training aims to develop a tolerant perception of diversity as well as accumulation and transfer of personal socially valuable cultural experience. Among the main objectives of multicultural training, we distinguish the development of cultural and multicultural competence. Many efforts are made in order to develop multicultural community values. The creation of conditions for the development of basic mechanisms for the formation of a global perspective for the existence and interaction of different cultures and styles are of considerable significance.

We define multicultural competence as the total capacity for productive life in multi-ethnic and multicultural society. It is the ability based on a combination of personal qualities, synthesised knowledge, and skills of positive inter-ethnic and intercultural interaction. Colarusso (2009) states that multicultural competence means the ability to adjust personal cultural background to heterogeneous cultural environment. Banks (1995) emphasises that this competence embraces human capacity for productive personal and 
professional interaction in the multilingual and multicultural environment. Therefore, we can summarise that multicultural competences include knowledge, skills and abilities as well as professional, social and cultural values, which are necessary for professional activities in the multicultural environment. Among its components, we determine multicultural skills and qualities, cross-cultural communication skills, knowledge of cultural universals, the appropriate behavioural roles and cultural capital. These competencies are developed in academic process and internship.

\section{Factors influencing the development of multicultural component of professional training in Canada}

While conducting our research we determined the main factors, which influenced the development of multicultural component of professional training in Canada. Among them are the growth of ethnic and racial consciousness, migration, qualitative and quantitative changes in demographics, globalisation, and expansion of international cooperation, science and technology advancement and improvements in the information sector.

The problem of smoothing negative effects of globalisation in tourism is one of the major concerns for international organisations, especially for World Tourism Organisation (WTO). No less important role belongs to tourism organisations in each particular country. There are both international associations and organisations established for purely internal purposes in Canada, namely Tourism Industry Association of Canada (TIAC), Travel and Tourism Research Association (TTRA), Canadian Tourism Commission (CTC), etc. Canada is characterised by excessive decentralisation, thus the provincial and territorial committees play the key role in tourism development.

Based on statutory documents of Canadian tourism organisations, statistical data, scientific researches into tourism and hospitality sphere, their basic functions were revealed (Martin, 2012). Among them are the development of strategic plans for the sector growth, representation of the industry at the national level and the support of large, small and medium-sized tourism businesses. It is important to mention that these institutions create information base of tourism attractions and events in Canada, support positive tourist image of the country at the international market, participate in the development of training programmes and their certification, publish research papers. They provide free access to the occupational standards of tourism, as well as develop electronic information database of vacancies and career opportunities.

In Canada the ability of tourism to create jobs and spread prosperity and innovation, encourage sustainable communities is unrivalled among other sectors. According to research release by the World Travel \& Tourism Council (WTTC, 2017), Canada's travel and tourism sector grew 50\% faster than the wider economy in 2017. Therefore, improving the quality of tourism business becomes a priority.

Professional activities of tourism and hospitality managers in Canada require specific skills, among which we determine the following ones: customer service taking into account ethnic, racial, age, gender, social and cultural differences; cooperation with communities of indigenous peoples, the development of rural areas, the involvement of new employees due to the lack of staff and rapid turnover. To meet the needs of the industry, professional training starts at the secondary school level. The early specialisation contributes to the extremely conscious choice of future career paths.

Despite the traditional view that tourism provides mainly low-paid and often seasonal work in the sector, in fact, it offers greater opportunities of business management and professional activities than most other industries. At the same time hospitality companies need to understand the uniqueness of their global workforce and recognise cultural differences as a source of their business success (Grobelna, 2015). Given the large variety of professional tasks necessary to provide tourism related services to customers, the development of tourism industry depends on skilled multi-task and educated staff that should study programmes providing real opportunities for gaining knowledge of other cultures and cultural differences and developing language and communication skills and abilities to work in a multicultural environment.

Therefore, to improve the system of training that would supply the reliable workforce for tourism and hospitality industry, it is necessary for authorities to consider certain challenges at provincial and national levels.

In Canada, provincial governments have recently developed new educational strategies aimed at the assurance of quality, accessibility, integrity, and congruence of training programmes with the industrial requirements. The main outcomes of such training should be the focus on providing high-quality service, competitiveness, productivity and sustainability; increased success of graduates involved in tourism programmes of proficiency training; coordination between training system and the industry, providing opportunities for continuous professional development for those already working in the field; training quality assurance for employers (Orton, 2001).

Each province and territory in Canada has developed its own educational structure, reflecting the features of the regions separated by large distances and differences in the historical and cultural heritage of the country. However, its thirteen education systems have much in common. 
Canada has turned tourism and hospitality into art, and many educational institutions train future managers for this dynamic sphere. Tourism has always played an important role in the economy of Canada. Now, every year millions of people visit hotels, restaurants, resorts, and clubs across Canada. This makes a substantial profit for the sector, which supports thousands of companies and jobs.

\section{Canadian experience in implementing multicultural component into THM professional training}

Colleges and Universities of Canada respond to the growing need for highly skilled employees by a large variety of programmes - from basic training in tourism and hospitality to doctoral degree programmes. Tourism and hospitality training in Canada has reached the highest international standards, integrating European and international traditions of quality and service, as well as the North American model of efficiency and the use of advanced technologies (Havran, Zhorniak, 2014).

Furthermore, Canadian system of post-secondary and higher education is based on the main principles of multicultural education. A detailed study of the Association of Universities and Colleges of Canada and Association of Canadian Community Colleges official websites revealed that their classical typology no longer covers the complex structure of Canadian post-secondary and higher education. The emergence of transfer programmes has formed a symbiotic relationship between colleges, universities, and programmes of pre-professional training. The practical aspects of training tied them more closely to their industry. Canadian universities offer undergraduate and graduate degree programmes, diplomas of various types (postsecondary, advanced, co-op, accelerated, CEGEP, etc.) and certificates for programmes of various levels of difficulty. Actually, the diversity in training levels and the principle of accessibility to educational programmes fully reflect the multicultural component of the Canadian tourism education.

Our analysis shows that the Canadian tourism professional training curriculum meets the requirements of both the modern post-secondary and higher education system as well as tourism and hospitality industry. The curriculum aims at acquiring intercultural competence, overcoming racism, sexism and other forms of prejudice and suppression at schools, using various forms and methods of evaluation in the recruitment, training, and assessment of educational levels, applying culturally sensitive kinds of explanations, gaining skills of social actions and increasing the understanding of global dynamics. In order to form multicultural component in Canadian tourism training curriculum, the following courses were developed: "Cross-cultural Management", "International Ecotourism", "Tourism for Indigenous Nations", "International Development of Adventure Tourism", "Intercultural Communication", "Types of Customers Behaviours", "Workplace Diversity" etc.

While analysing the content of professional tourism and hospitality training in Canadian universities we determined its main principles, which have strategic, pragmatic and operational value: the principle of consistency and continuity of academic process, flexibility and variability of educational programmes, interdisciplinarity, theoretically based experiential learning, and professionally oriented learning of tourism and hospitality managers according to demands of the labour market.

Zagonari (2009) states that professional training is mostly aimed at equipping students with "wellidentified transferable skills that students are able to demonstrate on completion of their curriculum" and that they "are more likely to learn how to learn in order to be flexible enough to cope with the changing skill requirements and the rapid technological advances" (p. 3). Meeting the diversity of the abovementioned requirements, besides traditional types of vocational training, universities and colleges in Canada deliver courses, seminars, training and mentoring practice. Mentoring is one of the most effective methods of strengthening the links between education and industry. We can divide it into three types - faculty advisory, industry mentoring and team projects.

Considering our findings in structure, content, forms, and methods of tourism and hospitality managers' training, it is important to focus on its multicultural aspect. Primary attention should be paid to:

- creation of favourable enrolment programmes for representatives of indigenous population and adaptation programmes for foreign students;

- involvement of community representatives in supervisory boards of higher education establishments,

- professional development programmes for university staff with compulsory study of indigenous peoples' culture;

- compiling individual course designs with the acknowledgement of various learning styles;

- involvement of students into community life during internship;

- study of cultural universals, use of various culturally sensitive methods for assessment of students' achievements.

Among the components of multiculturalism formation model we distinguish the following ones:

- objective (formation and development of culturally sensitive personal qualities, knowledge,

skills, intercultural communication; tolerance towards heterogeneity of society); 
- motivational (active attitude to learning, cognitive interest to other cultures, positive awareness of cross-cultural communication problem, identifying incentives that encourage active learning);

- content-based (implicit and explicit representation of multicultural component in the curriculum, the use of culturally sensitive types of explanation, taking into account occupational standards while developing the content of professional tourism training);

- organisational (creation of a single register of affordable multi-level vocational tourism training courses; close cooperation between business and educational tourism organisations, involvement of local communities, the introduction of industry mentoring into the proficiency training, use of appropriate forms and methods of multicultural knowledge formation, skills and types of awareness formation);

- diagnostic and evaluative (using various forms and methods of assessment; gradual diagnostic control of multicultural component formation, appropriate criteria and indicators for multicultural component formation, the comparative analysis of aims and outcomes.

The implementation of these components will result in formation of multicultural competence, tolerance and ability to successfully interact in a heterogeneous environment.

We define the advantages of the process of tourism professionals' multiculturalism formation in Canadian universities. Firstly, it is observance of consistency and continuity of the programmes and curricula at all levels of professional training of specialists in tourism (pre-professional, various certification and degree programmes). Secondly, it is the use of integrated forms and interactive teaching methods for the formation of multicultural competence (knowledge, skills, values, and attitudes). Thirdly, it is a studentcentred approach (development of an individual learning plan for each student). Next, it is the inclusion of disciplines selective component of the curriculum that enables students to better satisfy their individual needs in learning and demonstrate their abilities, as well as the significant prevalence of field-oriented courses and their multicultural focus. It is worth mentioning the trend to the increase in number of credits and learning hours for different types of practice that gives the students a real opportunity to consolidate their theoretical knowledge into practice and gain definite skills. Finally, it is mandatory involvement of the community in practical training.

The study of various THM training programmes of Canadian universities showed that the multicultural component is present at all levels of Canadian professional THM training and is fully compliant with international standards of educational qualifications in the field of tourism.

The results of this study indicate that Canadian system of post-secondary and higher education is based on three main principles of multicultural education. First is the principle of accessibility which implies provision of new educational grants and development of economic strategies to encourage families to save money for future higher education of their children, systematisation of information about training and setting up a system of lifelong learning, maximum application of IT in the sparsely populated province of Nova Scotia, the development of computer operating systems which use languages of indigenous nations in the Northwest Territories. The second principle is that of equal opportunities. There are programmes helping to overcome the language barrier for immigrants, indigenous peoples and international students, taking into account cultural differences of all participants in the educational process. The third principle is consideration of ethnic, racial, age, gender, and social differences - overcoming negative stereotypes, increasing the mobility of students, creating internationally competitive training programmes.

Our study made it possible to distinguish the fundamental knowledge, skills, professional values and understanding, which contain multicultural component: the ability to work at diversity workplace, obtaining intercultural verbal and non-verbal skills, care of people with special needs, identifying the target audience while implementing a marketing plan, respect for intercultural differences, determining demographic characteristics and motivational needs of customers, market analysis in terms of its cultural and demographic characteristics, ability to draw interest to the historical and cultural monuments, determine the impact of tourists flow on the local culture.

The choice of forms and methods of development of the multicultural component of professional tourism training depends on the qualitative characteristics (knowledge, skills or types of awareness) that educational activities are directed to. In order to generate knowledge about the multicultural aspects of tourist activity the most effective teaching methods are cognitive game, discussion, heuristic method and problem-based learning. The findings show that one of the most proper forms of the educational process is task-based integrated lecture and lecture-debate. The awareness of various cultural features is developed with the use of autobiographic and deductive methods, role-playing and heuristic discussion. Multicultural skills are introduced through case studies and practical classes while the best method for acquiring them is taskbased learning. 


\section{Conclusions}

We found out that multicultural training is an integral part of professional THM training in Canada with its diversity in training levels and the principle of accessibility of educational programmes. To avoid professional and educational encapsulation it is important for Ukraine to follow generally accepted guidelines in professional training, namely to take into consideration world trends in multiculturalism.

The findings of the present study will be beneficial for the further development of tourism and hospitality managers' professional training in Ukraine. The principle of consistency and continuity of academic process, the early specialisation starting from the secondary school, flexibility and variability of educational programmes, interdisciplinarity, theoretically based experiential learning, student-centred approach and professionally oriented learning of tourism and hospitality managers according to demands of the local and international labour market can be an effective means of improvement of Ukrainian THM training. The main principles of multicultural education in Canadian training, namely accessibility, equal opportunities and consideration of ethnic, racial, age, gender, and social differences, should be taken into consideration in creating competitive THM training programmes in Ukraine.

Further studies need to be carried out in order to validate the detailed insights into the implementation of multicultural training at the pre-professional level. The findings of our study complement those of earlier ones and provide valuable insights into the problem under research, especially, the multicultural competence of tourism and hospitality managers' development.

\section{References:}

Allport, G. (1963). Pattern and Growth in Personality (New edition). TX, USA: Harcout College Publishers.

Banks, J. (1995). Curriculum Guidelines for Multicultural Education In F. Schultz (Ed.), Multicultural Education: The Annual Edition Series (pp. 112-126). Guilford; Connecticut, USA: The Dushkin Publishing Group.

Banks, J. A. (2010). Multicultural education: Characteristics and goals In J. A. Banks, \& C. A. M. Banks (Eds.), Multicultural Education: Issues and Perspectives, (7th ed.) (pp. 3-32). Hoboken, USA: John Wiley and Sons, Inc.

Bethal, Ph. (1983). Gestalt and the Wisdom of the Kahunas. California, USA: DeVorss \& Company, Marine Del Rey.

Colarusso, D. (2009). Teaching English in the Global Age: Cultural Conversations (Doctoral dissertation). Retrieved January, 15, 2018 from https://tspace.library.utoronto.ca/bitstream/1807/18334/1/Colarusso_Dana_M_200911_PhD_thesis.pdf

Cross, W. (1991). Shades of Black: Diversity in African American Identity. Philadelphia, USA: Temple University Press.

Havran, M., Zhorniak, N. (2014). Polikulturnyi aspect profesiinoi pidhotovky vyshchykh navchalnykh zakladiv Kanady i Polshchi [Multicultural aspect of training in higher educational institutions in Canada and Ukraine]. Studies in Comparative Education, 4(22), 85-90.

Helms, J. E. (1990). Black and White Racial Identity Attitudes: Theory, Research, and Practice. Westport, CT, USA: Greenwood Press.

Grobelna A. (2015). Intercultural Challenges Facing the Hospitality Industry. Implications for Education and Hospitality Management. Journal of Intercultural Management, 7(3), 101-117. https://doi.org/10.1515/joim-2015-0023

MacLaurin, D. (2008). Tourism education in Canada. Journal of Teaching in Travel \& Tourism, 5(1-2), 1-25. https://doi.org/10.1300/j172v05n01_01

Manoharan, A. \& Singal M. (2017). A systematic literature review of research on diversity and diversity management in the hospitality literature. International Journal of Hospitality Management, 66, 77-91. https://doi.org/10.1016/j.jijhm.2017.07.002

Martin, T. (2012). Human Resource Module of the Tourism Satellite Account. Ottawa, Canada: Statistics Canada.

McLuhan, M. (1989). The Global Village: Transformation in the World Life and Media in the $21^{\text {st }}$ Century. NY, USA: Oxford University Press.

Hossain, Md. M., \& Aydin, H. (2011). A Web 2.0-based collaborative model for multicultural education. Multicultural Education \& Technology Journal, 5(2), 116-128. https://doi.org/10.1108/17504971111142655

Mukan, N., Kravets, S., \& Khamulyak, N. (2016). The analysis of content and operational components of public school teachers' continuing professional development in Great Britain, Canada, the USA. Comparative Professional Pedagogy, 6(2), 26-32. https://doi.org/10.1515/rpp-2016-0014

Orton, L. (2001). A New Understanding of Postsecondary Education in Canada. A Discussion Paper. Ottawa: Statistics Canada.

Percival, J. C., Cozzarin, B. P., \& Formaneck, S. D. (2013). Return on investment for workplace training: the Canadian experience. International Journal of Training and Development, 17(1), 20-32. https://doi.org/10.1111/ijtd.12002

Raymond, E. M., \& Hall C. M. (2008). The Development of cross-cultural (mis)understanding through volunteer tourism. Journal of Sustainable Tourism, 16(5), 530-543. https://doi.org/10.2167/jost796.0

Tourism Industry Association of Canada and Vise Canada. The Canadian Tourism Industry. (2012). A Special Report. Retrieved January, 15, 2018, from https://tiac-aitc.ca/_Library/documents/The_Canadian_Tourism_Industry_-_A_Special_Report_Web_Optimized_.pdf

World Travel \& Tourism Council (WTTC), (2017). Retrieved January, 15, 2018, from https://www.eturbonews.com/181001/canadastourism-grew-50-faster-than-the-economy-in-2017

Zagonari, F. (2009). Balancing tourism education and training. International Journal of Hospitality Management, $28,2-9$. https://doi.org/10.1016/j.ijhm.2008.03.006 